\title{
Spinal cord compression by extramedullary haematopoiesis in myelofibrosis
}

\author{
D. C. CRAWFORD* \\ M.B., B.S., M.R.C.P. \\ D. BATES* \\ M.A., F.R.C.P.
}

S. NIGHTINGALE*
B.Sc., M.R.C.P.

B. E. TOMLINSON $\dagger$

F.R.C.P., F.R.C.Path

*Department of Neurology, Royal Victoria Infirmary, Queen Victoria Road, Newcastle upon Tyne NE1 4LP and

$\nmid$ Regional Neurological Centre, Newcastle General Hospital, Newcastle upon Tyne

\begin{abstract}
Summary
A 50-year-old man with a 20-year history of myelofibrosis developed mild impairment of dorsal column sensation and ataxia of gait. A myelogram and subsequent peroperative biopsy demonstrated spinal cord compression due to extramedullary haematopoiesis. There was an excellent clinical response to surgery and radiotherapy. The characteristic clinical features and the pathogenesis of this unusual complication of myelofibrosis and extramedullary haematopoiesis are discussed.
\end{abstract}

KEY WORDS: paraplegia, myelopathy, radiotherapy.

\section{Introduction}

Intraspinal extramedullary haematopoiesis is an extremely rare cause of spinal cord compression, but one that should be considered in patients with myelofibrosis. We report such a patient, who developed cord compression due to extramedullary haematopoiesis and in whom complete remission followed surgical decompression and irradiation.

\section{Case report}

A 50-year-old bricklayer first sought medical attention in 1961 after noticing a mass in the left hypochondrium. Examination revealed gross splenomegaly and hepatomegaly. His haemoglobin was $16.9 \mathrm{~g} / \mathrm{dl}$ and there was a leuco-erythroblastic picture in the peripheral blood. Sternal marrow aspiration was unsuccessful. A diagnosis of myelofibrosis was made and later confirmed by trephine marrow biopsy. He received occasional short courses of busulphan ( $2 \mathrm{mg}$ daily) and was well until early 1980 when he began to complain of a sensation in the feet as though he were walking in thick woollen socks. By the early months of 1981 he had become progres- sively unsteady when walking and when standing in the dark or with his eyes shut. There was no back pain and no sphincter disturbance.

Examination revealed a $7 \mathrm{~cm}$ smooth, firm, nontender hepatomegaly and his spleen was enlarged to the umbilicus. Neurological examination showed loss of proprioception in the toes and of vibration sensation below the upper part of the sternum. There was a mild impairment to pin-prick and light touch sensation below the knees. His gait was unsteady and Romberg's sign was positive.

The haemoglobin was $16.4 \mathrm{~g} / \mathrm{dl}$ with a leucoe erythroblastic blood film. Other investigations in cluding radiographs of cervical, dorsal and lumbap spine and serum $B_{12}$ were within normal limits.

A lumbar myelogram was technically unsuccessful and a cervical myelogram (Fig. 1) demonstrated a complete block at D3 due to a concentric extradural lesion. Later films in which Myodil had descended into the thoracic theca suggested that the lesion extended to at least D12. A laminectomy of D2/3 was performed and a carpet-like rubbery tumour was found in the extradural space $5 \mathrm{~mm}$ in thickness surrounding the cord and extending antero-laterally. Histology confirmed the clinical diagnosis of extramedullary haematopoiesis.

Within days of the laminectomy and partial decompression the symptoms had improved. The patient was given a course of radiotherapy $(1,000$ rads in five divided doses over 7 days) to the thoracic spine and within 6 weeks was free of symptoms and had only mildly impaired vibration sensation in the legs.

\section{Discussion}

Extramedullary haematopoiesis is a common accompaniment of haematological disorders in particular myelofibrosis; it most commonly affects the liver, 


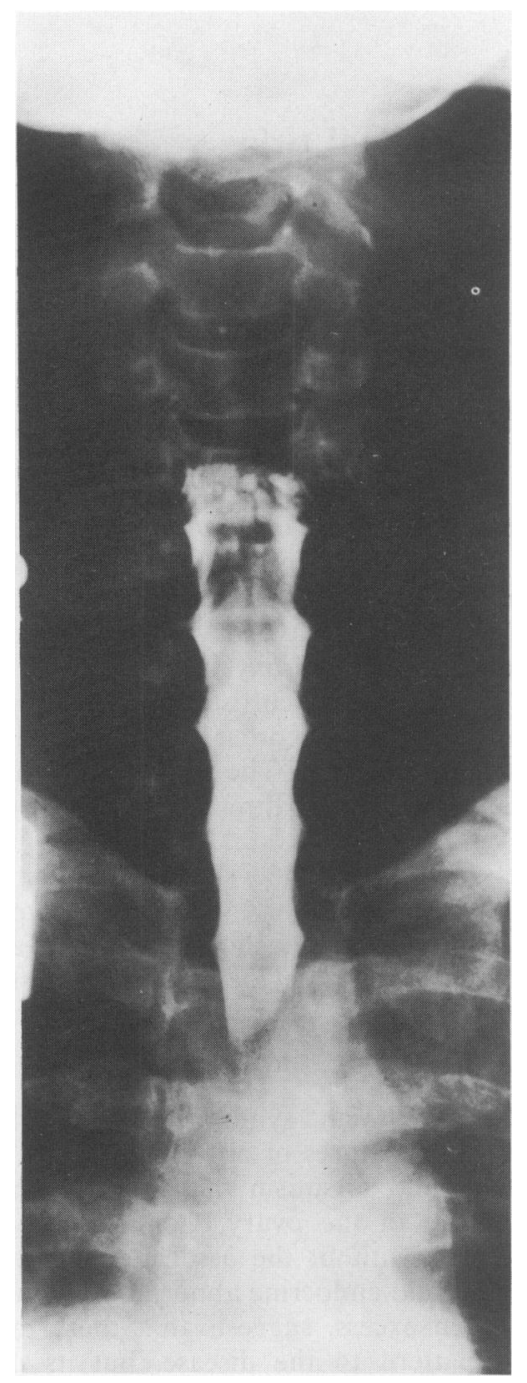

FiG. 1. Cervical myelogram shows complete block at D3 due to extramedullary erythropoiesis.

spleen, kidneys and adrenal glands (Ward and Block, 1971). Neurological complications from extramedullary haematopoiesis in the cranial or spinal dura are rare and there are very few reports of this occurring in association with myelofibrosis (Appleby et al., 1964; Bree, Neiman and Hodak, 1974; Close, Taira and Cleveland, 1958; Lowman, Bloor and Newcomb, 1963; Oustwani et al., 1980). The origin of the extramedullary haematopoietic tissue within the spinal canal is unknown, but various possibilities have been suggested (Appleby et al., 1964; Heffner and Koehl, 1970; Oustwani et al., 1980). It may reach the epidural space by embolization from the marrow. Extrusion of vertebral bone marrow into the epidural space is unlikely in the absence of vertebral erosion or fracture. Since intraspinal haematopoietic tissue may be associated with a paraspinal mass, it is possible that the former may have derived from direct spread of the latter through the intervertebral foramen. Alternatively haematopoietic tissue may develop in the epidural space from primitive rests (Heffner and Koehl, 1970).

The diagnosis of spinal cord compression by extramedullary haematopoiesis is confirmed by myelography, usually showing a complete block to the passage of contrast. Radiological changes in the bones at the level of the spinal cord lesion may be found (Appleby et al., 1964), though not in our case. Treatment is by decompressive laminectomy and radiotherapy. The response to treatment is usually excellent. Although it is to be expected that the highly radiosensitive bone marrow tumour will regress with radiation, it is perhaps surprising that the spinal cord recovers so well after prolonged compression. We feel that early diagnosis and treatment has important bearing on the likely outcome of this condition and would suggest that an evolving paraparesis in a patient with myelofibrosis should warrant early and full investigation in an attempt to diagnose a potentially curable condition.

\section{Acknowledgment}

We thank Dr R. B. Thompson for permission to report this case.

\section{References}

APPleby, A., BATSON, G.A., LASSMAN, L.P. \& Simpson, C.A. (1964) Spinal cord compression by extramedullary haematopoiesis in myelosclerosis. Journal of Neurology, Neurosurgery and Psychiatry, $27,313$.

Bree, R.L., Neiman, H.L., Hodak, J.A. \& FlynN, R.E. (1974) Extramedullary haematopoiesis in the spinal epidural space. Journal of the Canadian Association of Radiologists, 25, 297.

Close, A.S., Taira, Y. \& Cleveland, D.A. (1958) Spinal cord compression due to extramedullary haematopoiesis. Annals of International Medicine, 48, 421.

HEFFNER, R.R. \& KOEHL, R.H. (1970) Haematopoiesis in the spinal epidural space. Journal of Neurosurgery, 32, 485.

LOWMAN, R.M., BlooR, C.M. \& NeWCOMB, A.W. (1963) Roentgen manifestations of thoracic haematopoiesis. Diseases of the Chest, 44, 154.

Oustwani, E.K., Kurtides, E.S., Christ, M. \& Gric, I. (1980) Spinal cord compression with paraplegia in myelofibrosis. $\mathrm{Ar}$ chives of Neurology, 37, 389.

WARD, H.P. \& BLOCK, M.H. (1971) The natural history of agnogenic myeloid metaplasia and a critical evaluation of its relationship with the myeloproliferative syndrome. Medicine, 50, 357.

(Accepted 7 April 1983) 